\title{
Zoomorfismos, botanismos, gastronomismos: é assim que devem ser classificados os fraseologismos?
}

\section{Zoomorphisms, botanisms, gastronomisms: is that how phraseologisms should be classified?}

Lúcia Fulgêncio

Universidade Federal de Minas Gerais (UFMG), Belo Horizonte, Minas Gerais, Brasil luciafulgencio@gmail.com

Resumo: No estudo das expressões idiomáticas, emprega-se com frequência uma taxonomia que estabelece categorias fraseológicas com base na classe hiperonímica de um dos nomes que ocorrem na expressão. Dessa forma, costuma-se usar uma classificação que inclui termos como zoomorfismos, botanismos, indumentismos, somatismos e gastronomismos, por exemplo. Falar cobras e lagartos seria um zoomorfismo; por outro lado, plantar bananeira seria um botanismo. $\mathrm{O}$ presente artigo tem o objetivo de questionar a adequação e a pertinência de tal classificação. Apesar de esse uso constituir a praxe em vários estudos fraseológicos, acreditamos ser necessário rever a conveniência desse tipo de agrupamento taxonômico e discutir a pertinência da nomenclatura, tendo em vista, sobretudo, a não conformidade da classificação com o conteúdo semântico da expressão. Para questionar a adequação dessa classificação são apresentados argumentos como a falta de referência dos nomes internos às expressões idiomáticas e a impossibilidade de recuperação anafórica. Esses traços mostram a inconveniência de se estabelecer uma taxonomia com base em nomes cujos esquemas cognitivos não são evocados e cuja semântica individual não é preservada. Palavras-chave: expressão fixa; fraseologia; taxonomia dos fraseologismos; lexicologia. 
Abstract: In the study of idiomatic expressions, a frequently used taxonomy establishes phraseological categories based on the hyperonymic class of one of the nouns occurring in the expression. A classification has been proposed that includes terms such as zoomorphisms, botanisms, indumentisms, somatisms and gastronomisms, for example. Falar cobras e lagartos ('to speak ill of', literally 'to speak snakes and lizards') is considered a zoomorfism; on the other hand, plantar bananeira ('to stand on one's head', literally 'to plant a banana-tree') is considered a botanism. The present paper takes to question the adequacy and convenience of this kind of classification. Although this taxonomy has been used as praxis in many studies about phraseologisms, we believe that it is necessary to reconsider this kind of grouping and the adequacy of the nomenclature, mainly because of the non-conformity of the classification to the semantic content of the expression. We present arguments like the lack of reference of nouns found within the idiomatic expressions, and the impossibility of anaphoric recovering. Both features point out to the inconvenience of establishing a taxonomy based on words that correspond to no evoked schemata, and whose individual semantic content is not preserved.

Keywords: fixed expression; idiom; phraseology; taxonomy of idioms; lexicology.

Recebido em 20 de setembro de 2014. Aprovado em 04 de outubro de 2014.

\section{Introdução}

Os fraseologismos sempre despertaram a curiosidade das pessoas, mesmo dos não linguistas ${ }^{1}$. Recentemente tem-se verificado um incremento significativo na pesquisa sobre o comportamento dessas sequências linguísticas. Embora ganhem nomes variados nos diversos trabalhos e abordagens (como fraseologismos, idiomatismos, frasemas, expressões fixas, expressões idiomáticas e tantos outros), há sempre uma noção comum subjacente a todas essas terminologias: trata-se de grupos de palavras convencionais que se repetem consistentemente entre os falantes,

\footnotetext{
${ }^{1}$ Essa é também a opinião de Everaert, Linden, Schenk e Screuder, apresentada na introdução do livro Idioms (1995), p. 1.
} 
conhecidos por vários indivíduos tal qual qualquer palavra da língua e que, portanto, não são montados ou construídos no momento do enunciado. Ao contrário, são sequências de mais de uma palavra que são recuperadas da memória como um bloco ou um único item léxico ${ }^{2}$. Como diz Tagnin (2013, p. 19), "essas unidades são aprendidas como um todo, isto é, em bloco"; são convenções que caracterizam "o jeito como a gente diz".

Como exemplos de expressões fixas temos não somente as sequências constituídas por um sintagma verbal, como rodar a baiana, bater as botas, tirar de letra ou falar pelos cotovelos, mas também outros tipos de sequências de classes diferentes, como até mais ver, além do mais, corpo de delito, água oxigenada, ordem do dia, cá entre nós, de cabo a rabo, uma vez que, de qualquer forma, pra inglês ver, por assim dizer, nem vem que não tem, ou coisa que o valha, ora essa, e assim por diante, e tantas outras. Um levantamento dessas expressões fixas (FULGÊNCIO, inédito) revelou que são utilizadas no português brasileiro contemporâneo cerca de 8.000 expressões fixas.

Para o estabelecimento de uma taxonomia dos fraseologismos, encontramos de forma recorrente na literatura, em artigos e comunicações, uma tipologia das expressões que classifica os fraseologismos em classes intituladas zoomorfismos, botanismos, gastronomismos, indumentismos, somatismos e outras classes semelhantes. Essa tipologia leva em conta a semântica dos itens internos à expressão. Assim, se uma expressão inclui uma palavra referente a um animal, como brigar feito cão e gato, seria classificada como um zoomorfismo; se inclui uma planta, seria um botanismo, e assim por diante.

O presente artigo tem o objetivo de discutir a adequação de tal classificação. Apesar de esse uso constituir a praxe em vários estudos fraseológicos, acreditamos ser necessário rever a conveniência desse tipo de agrupamento taxonômico e discutir a pertinência e a conveniência da nomenclatura, tendo em vista, sobretudo, a sua não conformidade com o significado da expressão, tomada como um todo. Por exemplo, se eu digo que deu um bode no meu trabalho, será que estou falando de um animal? Se não, que sentido teria classificar dar um bode como um zoomorfismo?

Para questionar a adequação dessa classificação são apresentados argumentos como a falta de referência dos nomes internos às expressões

\footnotetext{
${ }^{2}$ A respeito da definição de "expressão fixa", veja-se a tese Expressões fixas $e$ idiomatismos do português brasileiro contemporâneo (FULGÊNCIO, 2008).
} 
idiomáticas e a impossibilidade de recuperação anafórica, que seriam traços que apontam para a inconveniência de se estabelecer uma taxonomia com base em nomes que não são evocados e cuja semântica individual não é preservada.

A análise apresentada tem orientação metodológica descritivista, e como arcabouço teórico apoia-se sobretudo nos trabalhos de Tagnin (1989, 2013), Gross (1996) e Fulgêncio (2008).

\section{Entendendo a classificação}

Para compreender a base da categorização dos fraseologismos em classes como zoomorfismos ou botanismos, vamos exemplificar como são distribuídas as expressões segundo essa taxonomia. Teríamos classes como as seguintes, que incluiriam expressões como as exemplificadas no quadro 1 a seguir:

Quadro 1 - Taxonomia dos fraseologismos como usada em alguns trabalhos

\begin{tabular}{|c|c|c|c|}
\hline \multicolumn{4}{|c|}{ Exemplos de classes } \\
\hline $\begin{array}{c}\text { Zoomorfismos / } \\
\text { zoônimos }\end{array}$ & Somatismos & Botanismos & Indumentismos \\
\hline $\begin{array}{c}\text { matar cachorro a } \\
\text { grito }\end{array}$ & $\begin{array}{c}\text { não dar o braço a } \\
\text { torcer }\end{array}$ & $\begin{array}{c}\text { saber com quantos } \\
\text { paus se faz uma } \\
\text { canoa }\end{array}$ & rasgar seda \\
\hline pagar mico & ser unha e carne & $\begin{array}{c}\text { chutar o pau da } \\
\text { barraca }\end{array}$ & bater as botas \\
\hline $\begin{array}{c}\text { falar cobras e } \\
\text { lagartos }\end{array}$ & $\begin{array}{c}\text { botar a boca no } \\
\text { trombone }\end{array}$ & $\begin{array}{c}\text { plantar bananeira } \\
\text { de aranha }\end{array}$ & $\begin{array}{c}\text { ficar na barra da } \\
\text { saia }\end{array}$ \\
\hline $\begin{array}{c}\text { estar prar a língua } \\
\text { engolir sapo }\end{array}$ & $\begin{array}{c}\text { ser pau pra toda } \\
\text { obra }\end{array}$ & $\begin{array}{c}\text { botar no chinelo } \\
\text { levantar a cabeça }\end{array}$ & $\begin{array}{c}\text { não ser flor que se } \\
\text { cheire }\end{array}$ \\
$\begin{array}{c}\text { botar as } \\
\text { manguinhas de } \\
\text { fora }\end{array}$ \\
\hline
\end{tabular}

Observa-se que a classificação proposta é estabelecida a partir de divisões que levam em conta um dos nomes presentes no interior da expressão. A taxonomia estabelece então categorias fraseológicas com base na classe hiperonímica de um desses nomes. Falar cobras e lagartos seria um zoomorfismo (ou um zoônimo) porque inclui na sua composição os animais cobras e lagartos. Assim também o grupo estar 
em palpos de aranha foi classificado como zoomorfismo ${ }^{3}$, apesar de a palavra palpo geralmente não ser utilizada nem compreendida fora dessa expressão. Ainda de acordo com essa proposta de taxonomia, a expressão rasgar seda (que significa "bajular") seria um indumentismo, por incluir a palavra seda que, no seu sentido literal fora da expressão se refere a um tecido; e meter o pau (que significa "falar mal de alguém") seria um botanismo, como se vê no quadro 1. Assim, de acordo com essa classificação, pagar o pato é um zoomorfismo pelo simples fato de incluir a palavra pato, mesmo se o pato não foi evocado e não entrou na história. E chutar o pau da barraca seria um botanismo porque dentro dessa expressão aparece a palavra pau - que tem a ver com árvore e, portanto, é uma planta-, mesmo que um pau de barraca de verdade nem seja de madeira, mas de metal.

O que leva a incluir uma expressão num grupo ou em outro, como zoomorfismo ou botanismo ou qualquer outra classe, é o significado literal do nome que aparece na expressão. Para tal tipologia é preciso, portanto, "desconstruir" a expressão - que, como sabemos, em muitos casos tem um significado não correspondente à soma da semântica individual dos elementos integrantes da expressão - e dela pinçar um dos itens que entram no conjunto idiomático.

O que se pretende discutir aqui é a relevância dessa classificação - ou mais que isso - a adequação dessa taxonomia. Até onde vemos, esse tipo de taxonomia apresenta vários inconvenientes e sua utilização parece não ser útil para análises linguísticas. Vamos examinar a seguir alguns dos problemas envolvidos nessa classificação.

\section{Primeiro questionamento}

$\mathrm{O}$ primeiro questionamento quanto à taxonomia apresentada anteriormente pode ser formulado com a pergunta seguinte: se essa taxonomia fosse adequada, como seria possível classificar as expressões que não contêm internamente nenhum nome? Como classificar, por exemplo, um fraseologismo como levar a mal? Ou até mais ver, falar grosso, dar a entender, falar por falar, fazer com que ou vamos e venhamos? Esses casos e várias outras expressões fixas não incluem

\footnotetext{
${ }^{3}$ A expressão estar em palpos de aranha foi classificada como zoomorfismo no artigo de Budny e Durão (2013).
} 
nomes. Se adotássemos uma tipologia que se baseia na significação de um nome integrante da expressão, como classificar as expressões que não contêm nomes? Obviamente não seria possível encaixar esses fraseologismos em classe nenhuma. Só esse fato já seria suficiente para indicar uma falha classificatória significativa, porque mostra a incapacidade do modelo de estabelecer uma taxonomia que seja realmente capaz de classificar todos os casos.

E não são poucas as expressões fixas que não incluem nomes. Vejamos como exemplo o texto seguinte:

(1) De vez em quando eu tenho insônia, ou melhor, eu custo a pegar no sono. Mas no final das contas eu apago. Quer dizer, eu sempre acabo dormindo.

As expressões em itálico de vez em quando, ou melhor e quer dizer, todas de alta frequência na língua, não incluem nenhum nome. Como classificá-las?

É preciso considerar que a estrutura da expressão fixa nem sempre é um sintagma verbal. Nem sempre a expressão é do tipo pagar o pato, onde se encontra um verbo seguido de um complemento que inclui um nome. Fraseologismos como falar cobras e lagartos ou chutar o balde representam somente $u m$ dos tipos de fraseologismo. Uma expressão fixa é na verdade qualquer sequência convencional memorizada em bloco pelos falantes e, portanto, constitui uma unidade da memória lexical. Para que uma sequência lexical seja uma expressão fixa basta que essa sequência seja convencional e memorizada - seja o significado opaco ou transparente, seja a expressão iniciada por um verbo ou por outro termo qualquer, e quer inclua um nome ou não.

Há muitos agrupamentos convencionais, muitas expressões de categorias diversas, algumas usadas inclusive como elementos coesivos, outras com função pragmática de interação entre os falantes, e muitas dessas não incluem internamente nenhum nome, como, por exemplo, as seguintes: a bem dizer, ou seja, que nem, a três por dois, de mais a mais, digamos assim, até mais ver, não há de quê, de nada, e por aí vai (inclusive). Em nenhum desses exemplos encontramos nomes que pudessem servir de base para a inserção dessas expressões em uma das classes, considerando uma taxonomia que se fundamenta na presença de um nome na expressão. Nos casos em que a expressão fixa não inclui um elemento nominal, o encaixamento da expressão em uma das classes ficaria impossibilitado. 
Conclui-se então que a classificação como zoomorfismo, botanismo etc. apresenta, inicialmente, o sério problema de não dar conta dos dados, porque depende da presença de um nome que às vezes não está lá.

\section{Segundo questionamento}

Continuando a investigação sobre a adequação da taxonomia, poderíamos perguntar: na hipótese de haver um nome presente na expressão, será que a classificação como zoomorfismos, botanismos etc. seria adequada? Na tentativa de salvar a taxonomia pelo menos nos casos em que o fraseologismo inclui um elemento nominal, vamos examinar se nessa eventualidade a classificação como zoomorfismos e assemelhados se sustentaria.

Para o exame dessa possibilidade, é necessário levar em conta a seguinte observação: no grupo das expressões fixas aparecem palavras que só são usadas na expressão, e não são empregadas independentemente, fora da expressão, em sintagmas construídos pelos falantes. Nem sempre os nomes incluídos nos idiomatismos têm significado individual, isolado da expressão, do ponto de vista sincrônico. Assim, um fato que se constata ao analisar as expressões fixas é que muitas delas incluem palavras que só são usadas dentro do grupo idiomático, como por exemplo: ficar ao léu, fazer jus, meter o bedelho, misturar al hos com bugalhos, dar na veneta, por um triz, por conseguinte, sem eira nem beira, ledo engano, a granel, de bom grado, não obstante, terreno baldio e desta feita. Em todas essas expressões há palavras que hoje em dia não são usadas (marcadas em negrito, nos exemplos citados). Se perguntamos a um falante nativo o que significa léu, bugalho ou eira, por exemplo, provavelmente vamos propor uma questão de difícil solução. Isso porque essas palavras, tomadas como itens independentes, fora da expressão, não têm significado autônomo do ponto de vista sincrônico. São palavras que atualmente já não têm vida própria e já perderam o conteúdo semântico individual na língua contemporânea.

Obviamente toda expressão fixa teve uma origem e provavelmente, lá no passado, as palavras que integram o que hoje é uma expressão fixa devem ter tido uma carga semântica que motivou a construção. É provável que inicialmente tenha havido uma lógica composicional na formação semântica do grupo, mas atualmente, no português brasileiro 
contemporâneo, essa carga semântica individual já se perdeu. É lícito supor que, quando as atuais expressões foram construídas pela primeira vez, foram utilizadas palavras que, provavelmente, tinham um significado independente conhecido na época. Porém, hoje em dia - ou seja, do ponto de vista estritamente sincrônico - palavras como léu, esmo, bedelho, bugalhos, veneta, triz, conseguinte, eira, ledo, granel, grado, obstante, baldio e feita (no feminino) não têm independência semântica nem sintática e só são empregadas como elementos constitutivos de uma expressão fixa.

Então, trazendo casos como esses para o contexto da taxonomia dos zoomorfismos e assemelhados, a pergunta que se faz é a seguinte: como classificar expressões como dar na veneta ou ficar ao léu, tomando como base o significado dos nomes veneta e léu, se esses nomes sincronicamente não possuem conteúdo semântico individual? Como classificar expressões como as citadas acima, com base no significado de elementos que perderam sua independência e que contemporaneamente não podem mais ser considerados itens léxicos autônomos? Como classificar a partir de um termo cujo significado individual não é reconhecido pelo falante?

\section{Terceiro questionamento}

O terceiro questionamento leva em conta a própria definição de expressão idiomática. O termo expressão idiomática refere-se a um grupo de palavras (como ser todo ouvidos ou fazer uma tempestade em copo d'água, por exemplo) cujo significado é idiossincrático, não composicional, de modo que a soma do significado unitário das palavras que compõem a sequência não leva ao significado global do grupo. Mesmo se todas as palavras integrantes da expressão são conhecidas, o significado do grupo não é obtido a partir do cômputo do significado interno individual de cada um dos seus membros.

Mel'čuk (1995) expressa essa ideia dizendo que "um idiomatismo $\mathrm{AB}$ de L é um frasema semântico tal que o seu significado ' $X$ ' não inclui nenhum dos significados 'A' e 'B' de A e B em uma posição dominante.”4

\footnotetext{
${ }^{4}$ No original: "An idiom $\mathbf{A B}$ of $\mathbf{L}$ is a semantic phraseme such that its signified ' $\mathrm{X}$ ' does not include either of the signifieds 'A' and 'B' of $\mathbf{A}$ and $\mathbf{B}$ in a dominant position." (MEL'ČUK, 1995, p. 181).
} 
Dito de outra forma, isso quer dizer que as expressões fixas são unidades lexicais em que não há computação de significado, uma vez que o significado total do grupo não inclui o significado individual de cada um dos seus membros. Isso acontece porque o significado do fraseologismo já está pronto, já está determinado na língua. A interpretação semântica da expressão é convencional e independe do significado de cada uma das palavras que a compõem. Como explica Alvarez (2000), num fraseologismo "o significado é dado pelo conjunto de seus elementos".

Portanto, se os fraseologismos não guardam relação com o significado individual de seus membros, como justificar uma classificação feita com base na semântica individual desses membros? Como estabelecer uma taxonomia com base no significado de palavras que, por definição, não são computadas no significado?

Algumas expressões fixas até dizem o contrário do que seria de se esperar se fosse feita uma computação interna. Por exemplo, um sem número de vezes não quer dizer "zero vezes", mas justamente o contrário ("muitas vezes"); se uma pessoa fica com os olhos rasos d'água quer dizer que tem "os olhos cheios d'água", e não "com pouca água", como poderia sugerir a presença do qualificativo rasos. E não se pode deixar de mencionar as famosas expressões pois não e pois sim, que significam justamente o contrário do que se poderia esperar, caso fosse feita a computação do significado de cada palavra. Não há dúvida de que, sempre tomando a perspectiva sincrônica, a estruturação de um fraseologismo independe do significado estrito dos elementos que compõem a sequência.

Outra questão relacionada à idiomaticidade e à idiossincrasia semântica das expressões idiomáticas tem a ver com o desvio metodológico de certas ilustrações publicadas em livros didáticos, divulgadas também na internet, que certos autores ou professores tentam utilizar para o ensino dos fraseologismos, sobretudo quando se trata da aprendizagem de línguas estrangeiras. A estratégia consiste em apresentar uma expressão idiomática e, paralelamente, uma ilustração que recupera o significado literal do grupo. Por exemplo, para a expressão vai plantar batata! apresenta-se um desenho que reproduz uma pessoa no campo, agachada na terra, realmente plantando batatas ${ }^{5}$. Ora, isso é justamente

${ }^{5}$ Como feito no livro de ensino de português para estrangeiros de Henriques e Grannier (2001, p. 103). 
o que a expressão não quer dizer. Isso é justamente o oposto do que se deveria esperar em uma atitude didática, ou seja, é a relação semântica que se desejaria evitar, uma vez que o significado literal é justamente o significado não evocado pela expressão. Vejam-se, como exemplificação, as ilustrações a seguir, apresentadas no livro para o ensino de português para estrangeiros de Henriques e Grannier (2001, p. 16 e 51).
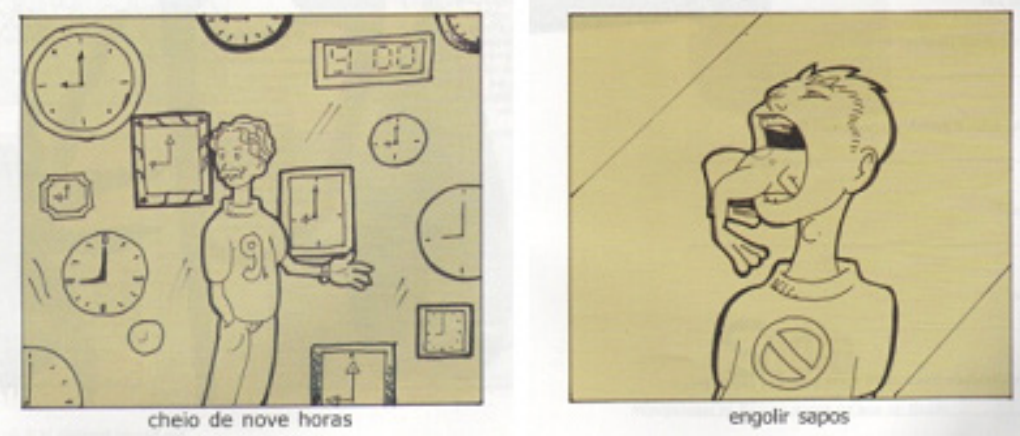

Esse tipo de relacionamento semântico parece ser o que não se deveria propor a um aprendiz e, ao que tudo indica, uma exercitação inconveniente do ponto de vista pedagógico. Esse tipo de estratégia relacionando a expressão a desenhos que não apresentam o significado da expressão parece claramente inadequado para fins didáticos, uma vez que deturpa o significado da expressão. A evocação do significado literal proposto pela figura não é, definitivamente, o que leva ao significado do fraseologismo. Numa expressão fixa, como bem se sabe, o significado do grupo é estabelecido por convenção, e não é montado composicionalmente, como sugerido pela ilustração. Trata-se, portanto, de uma estratégia didática equivocada para o ensino de uma expressão em língua estrangeira. É fácil verificar que o exercício é desastrado, uma vez que reforça com a imagem justamente aquilo que a expressão não diz, e impõe uma compreensão individual de cada palavra, como se o processamento composicional fosse efetivo; ao contrário, a computação linear do significado individual de cada palavra é justamente a atitude que se desejaria evitar que o aluno desenvolvesse. 


\section{Quarto questionamento}

A pergunta que leva à quarta consideração é a seguinte: no caso de expressões transparentes, haveria a computação do nome interno à expressão?

Antes de mais nada, é preciso salientar que, diferentemente do que em geral se pensa, nem todas as expressões fixas são opacas. Há também expressões fixas transparentes.

Observamos até agora as expressões opacas, que possuem significado idiossincrático, diferente daquele que seria de se esperar caso fosse efetuada uma computação semântica de cada palavra do grupo idiomático. Expressões opacas seriam, por exemplo, pagar mico, bater as botas, aos trancos e barrancos, dar zebra, levantar a lebre, com a avó atrás do toco, cheio de nove horas e da pá virada. Em casos como esses, o significado do grupo é bastante diferente do que aquele que seria obtido com a soma do significado individual de cada elemento. Não há computação de significado e, portanto, é nitidamente sem sentido dizer que pagar o pato é um zoomorfismo (ou um zoônimo), que bater as botas deveria ser classificado como um indumentismo, e que aos trancos e barrancos seria talvez um geologismo ou coisa parecida. No caso das expressões opacas fica claro: se o significado do bloco idiomático não leva em conta o significado das palavras componentes, então não faz sentido estabelecer uma classificação baseada justamente no significado de componentes que não entram no significado da expressão, como comentado anteriormente. Mais ainda: o significado dos itens componentes é até mesmo incompatível com o significado do bloco idiomático.

Mas há também expressões com composição não totalmente opaca. Trata-se sem dúvida de uma expressão fixa, já que o significado é convencional e a formação do grupo é rígida (mais rígida do que em casos de composição livre da língua); mas em tese seria possível retraçar um caminho que levaria à lógica na formação semântica do grupo. Um ouvinte que nunca tenha tido contato anterior com um fraseologismo transparente seria capaz de interpretá-lo, ao contrário do que acontece com fraseologismos opacos. São exemplos de expressões fixas transparentes casos como brigar feito cão e gato, dar água na boca, cara ou coroa, par ou ímpar, surdo-mudo, de alto a baixo e achados e perdidos. 
Exemplos como esses podem nos levar a pensar: quem sabe nesses casos de expressões transparentes seria válido classificar a expressão como zoomorfismo, botanismo etc. com base no nome presente numa sequência idiomática transparente? Nossa resposta é que nem nesses casos seria plausível impor uma classificação com base no elemento nominal, porque numa expressão fixa não há evocação dos referentes dos nomes internos à expressão, mesmo em se tratando de expressões transparentes.

Como explicam Perini et al. (1996), um SN composto pelo falante (isto é, não idiomático) é estruturado em torno de um nome que tem potencial referencial e constitui o núcleo do sintagma. Essa seria a estruturação de um SN construído pelo falante, mas o mesmo não acontece nos casos de fraseologismos, como se vê pela falta de referenciação dos nomes internos à expressão e pela impossibilidade de retomada anafórica. É o que veremos a seguir.

\subsection{A falta de referenciação dos nomes nas expressões fixas}

Para observar a falta de referência dos nomes que compõem uma expressão fixa vamos tomar para exemplificação as locuções idiomáticas referenciais água-marinha e boca de lobo. A expressão como um todo é referencial, mas o que se deve notar é que os nomes internos água e boca não são evocados na composição do significado do grupo, como mostrado na análise que se segue:

$$
\begin{array}{rlr}
\text { água-marinha } \rightarrow & \text { referente do SN: } & \begin{array}{c}
\text { um tipo de pedra } \\
\text { preciosa azul } \\
\text { água (referente não } \\
\text { referente do núcleo }:
\end{array} \\
& \text { acionado) }
\end{array}
$$

$$
\begin{aligned}
& \text { boca de lobo } \rightarrow \quad \text { referente do } \mathrm{SN}: \quad \text { bueiro grande } \\
& \text { referente do núcleo : boca ("parte do corpo" } \\
& \text { - referente não acionado) }
\end{aligned}
$$

Em casos de expressões fixas como essas, só é evocado o referente do SN completo, isto é, o significado global do grupo referencial. No caso de boca de lobo, por exemplo, o único significado acionado é o de "bueiro"; por outro lado, o referente de boca ("parte do corpo") e o referente de lobo (“determinado animal") não são evocados juntamente com a expressão. 
Os esquemas cognitivos individuais de cada palavra da expressão não são ativados e a semântica individual de cada termo não é preservada.

Em sintagmas construídos pelo falante, por outro lado, o processamento é diferente. Por exemplo, se eu me refiro à bolsa $d a$ Maria (que tem uma estrutura sintática correspondente à de boca de lobo), o referente de todo o sintagma e também o referente de Maria são ambos acionados na mente do ouvinte. Tanto é assim que é possível fazer referência a Maria posteriormente no discurso, como se vê no exemplo seguinte:

(2) A bolsa da Maria está pesadíssima. Ela gosta de carregar tudo, porque $\varnothing$ acha que sempre $\varnothing$ pode precisar de alguma coisa.

Vê-se, portanto, que os fraseologismos têm um comportamento diferente também quanto à possibilidade de evocação do referente dos nomes internos à expressão: o referente dos nomes que compõem um SN composicional (construído pelo falante) são acionados, mas o referente dos nomes que compõem uma expressão fixa não são acionados.

\subsection{A impossibilidade de retomada anafórica}

Uma comprovação de que os referentes dos nomes que compõem uma expressão fixa não são acionados pode ser demonstrada pelo fato de que, por exemplo, na expressão boca de lobo, o referente de boca não pode ser retomado anaforicamente. Vejamos:

(3) *O Fernando caiu com o carro numa boca de lobo, e eu consertei a minha $\varnothing$ que tinha uns dentes encavalados.

[Ø = "boca" (nome interno à expressão boca de lobo)]

A impossibilidade de retomada anafórica do referente de boca comprova que o significado individual desse item e o esquema cognitivo correspondente não são acionados pela expressão.

E o de lobo também não:

(4) *A boca de lobo estava aberta, sem tampa. E na história tinha um $\varnothing$ que queria comer os três porquinhos.

[Ø = "lobo" (nome interno à expressão boca de lobo)] 
A agramaticalidade dos exemplos (3) e (4) demonstra a não ativação dos esquemas cognitivos dos nomes que integram uma expressão fixa.

A impossibilidade de retomada anafórica dos referentes de nomes que compõem um fraseologismo se verifica não somente em casos de elipse, mas também fica impedida a retomada através de anáfora pronominal. Por exemplo:

(5) A Ana vive reclamando e fazendo tempestade em copo d'água. *Ela é sempre acompanhada de ventos.

Como as expressões fixas são memorizadas com o seu significado global, como um único item léxico, não há cômputo interno, nem semântico nem sintático. Portanto, nas expressões fixas não há ativação do referente do nome, nem esse referente do nome pode ser retomado anaforicamente 6 . Se é assim, quando se diz

(6) Vou ter de rever todas as contas, porque deu um bode na contabilidade.

perguntamos: seria adequado classificar a expressão dar um bode como um zoomorfismo ou zoônimo, se o animal "bode" não foi acionado na mente dos interlocutores?

\section{Quinto questionamento: consequências}

Vamos examinar se a classificação como zoomorfismo, botanismo etc é inócua ou se leva a consequências inadequadas do ponto de vista da pesquisa linguística.

Uma primeira inconveniência quanto a esse tipo de classificação consiste no fato de que a taxonomia proposta agrupa juntas, na mesma classe, expressões cujo significado não tem nada em comum. Por

\footnotetext{
${ }^{6}$ Ressalvem-se casos de jogos de palavras, em que a retomada de um elemento interno à expressão fixa representa uma transgressão intencional, provocada de propósito pelo autor, para criar humor ou interesse literário. Nesse caso o humor se instaura justamente pelo reconhecimento do desvio quanto ao processamento convencional. Um exemplo de retomada anafórica de nome interno à expressão fixa, reconhecida pelo ouvinte/leitor como um desvio proposital do autor com a intenção de brincar com a língua, aparece no seguinte texto: "Cid Moreira não é de engolir sapos. Mas, desde a adolescência, adora colecioná-los.” (Revista Caras ed. 672, ano 13, n’ 38).
} 
exemplo, ficariam juntas na classe dos indumentismos os fraseologismos bater as botas (que significa "morrer") e rasgar seda (que significa "elogiar"). Vê-se que o significado dessas duas expressões não tem pontos em comum, apesar de incluídos na mesma classe.

A taxonomia sugerida não leva em conta o significado do fraseologismo. A classificação se baseia no significado de uma das palavras da expressão, e não no significado do bloco idiomático. Porém, como vimos, só é acionado na mente dos interlocutores o significado do grupo como um todo; só esse significado global é o que realmente conta - mas justamente esse significado do bloco não é levado em consideração ao se estabelecer a classificação, segundo a taxonomia analisada.

$\mathrm{O}$ inconveniente mais grave refere-se ao fato de essa taxonomia levar a pensar que classes como zoomorfismos ou botanismos incluiriam traços comuns ou indicariam comportamentos semelhantes entre seus membros, ou seja, entre as expressões incluídas em cada classe; isso, no entanto, não se verifica, e assim a classificação proposta pode induzir a falsas conclusões.

Existe realmente a tendência a supor que as expressões de cada classe partilhariam traços comuns, tanto é que já houve a sugestão de criação de um dicionário bilíngue só de somatismos, como proposto por Rocha e Silva (2014). As autoras indicam assim a pressuposição de que haveria algo em comum nas expressões incluídas dentre os assim chamados somatismos, o que justificaria a confecção de um dicionário para aprendizes de língua estrangeira com somente expressões que incluem nomes relativos a partes do corpo.

Há ainda outros trabalhos que examinam um fraseologismo e traçam conclusões para toda a classe dos zoomorfismos ou botanismos. Mas, como vimos, classes como essas agrupam expressões muito diferentes, que na verdade não têm características comuns a não ser o fato de incluírem um nome que, fora do grupo idiomático, remete a um animal ou planta, por exemplo - mas que dentro da expressão não carrega esse significado. $\mathrm{O}$ que acontece com uma determinada expressão não é extensível para a classe dos chamados somatismos, zoomorfismos e assemelhados, porque tais classes não têm características partilhadas nem comportamentos semelhantes ${ }^{7}$. Ao ampliar para toda a classe uma

${ }^{7}$ O artigo de Budny e Durão (2013) investiga como os dicionários apresentam as chamadas "unidades fraseológicas com zoônimos". Com isso, as autoras parecem 
característica de uma expressão, corre-se o risco de chegar a uma análise linguística inconveniente, tendo em vista que as classes propostas não possuem uniformidade semântica nem traços linguísticos em comum.

Outros trabalhos procuram estabelecer a maior ou menor facilidade de aquisição de expressões de uma determinada classe: se os zoomorfismos ou os botanismos ou os indumentismos seriam mais fáceis de serem compreendidos. Mas o que determina a facilidade de montagem do significado no caso do primeiro contato com a expressão é a sua opacidade ou transparência, individualmente ou dentro do contexto discursivo, e não o tipo de elemento constitutivo (se é um animal ou planta, por exemplo). O ouvinte que nunca entrou em contato com uma expressão tenta construir sentido, e se a expressão é transparente ou inserida num contexto que leva facilmente a um significado, essa expressão será mais facilmente compreendida, independentemente de conter o nome de um bicho, de uma planta ou de uma parte do corpo.

\section{Conclusão: como classificar os fraseologismos?}

Os fatos aqui comentados nos levam a crer que uma classificação como zoomorfismo, botanismo, indumentismo etc. é inadequada porque não apresenta uma classificação lógica e útil do ponto de vista linguístico e, além disso, pode levar a falsas relações e a conclusões linguísticas não confiáveis.

A solução? Como classificar as expressões fixas?

Em primeiro lugar, é preciso considerar que há várias formas de classificar, dependendo do objetivo. Por exemplo, do ponto de vista lexicográfico (isto é, da confecção de dicionários e glossários), a classificação pode ser diferente daquela que leva em conta o ponto de vista da pesquisa lexicológica.

Uma taxonomia do ponto de vista lexicológico, apoiada em critérios semânticos, implicaria o agrupamento onomasiológico, que se baseia no significado do grupo fraseológico como um todo - que é o único evocado - e não no significado das palavras individuais que compõem a expressão.

supor algum tipo de comportamento comum que justificasse o recorte. Na verdade, o que acontece com uma expressão que inclui o nome de um animal não é passível de generalização para o restante da classe. Mas o tipo de taxonomia proposto induz a pensar que haveria alguma uniformidade entre as sequências idiomáticas do grupo. 
Assim, uma taxonomia do tipo onomasiológico deveria colocar juntas, na mesma classe, as expressões bater as botas e esticar as canelas, uma vez que ambas remetem ao mesmo significado: "morrer". E não classificar bater as botas como indumentismo e esticar as canelas como somatismo, colocando expressões de mesmo significado em classes distintas.

Essa é a proposta apresentada por Riva (2013) em seu dicionário, que parece bem mais coerente e útil para os linguistas, no estudo dos fraseologismos. Ressalte-se, entretanto, que se trata de uma classificação interessante para fins de pesquisa linguística e para estudiosos do fenômeno, mas pode não ser a mais adequada para fins lexicográficos, quando o dicionário se destina à consulta de termos desconhecidos. Na prática, o consulente geralmente usa o dicionário para a obtenção do significado quando encontra em um texto uma palavra ou um grupo de palavras que não consegue compreender. Nesse caso, uma taxonomia onomasiológica, que parte justamente do significado para o agrupamento das expressões, não é de auxílio ao leitor (ou ouvinte) que não sabe o significado da expressão.

A taxonomia pode ser variada dependendo do objetivo da classificação, mas seja como for é indispensável que possua justificativa linguística e coerência interna.

\section{Referências}

ALVAREZ, M. L. O. Expressões idiomáticas do português do Brasil e do espanhol de Cuba: estudo contrastivo e implicações para o ensino de português como língua estrangeira. 2000. $334 \mathrm{f}$. Tese (Doutorado) Instituto de Estudos de Linguagem, Universidade Estadual de Campinas, Campinas, 2000. Disponível em: $<$ http://www.bibliotecadigital.unicamp. br/document $/$ ?code $=$ vtls000215016 $>$. Acesso em: 20 set. 2014.

BUDNY, R.; DURÃO, A. B. de A. B. Unidades fraseológicas com zoônimos: apresentação e localização em dicionários monolíngues e equivalentes de tradução em dicionários bilíngues. Caligrama, Belo Horizonte, v. 18, n. 2, p. 89-103, jul.-dez. 2013. Disponível em: $<$ http:// periodicos.letras.ufmg.br/index.php/caligrama/article/view/4921/4809>. Acesso em: 20 set. 2014.

EVERAERT, M.; LINDEN, E.; SCHENK, A.; SCHREUDER, R. (ed.). Idioms: structural and psychological perspectives. Hillsdale (NJ): Lawrence Erlbaum Associates, 1995. 
FERREIRA, A. B. de H. Novo dicionário eletrônico aurélio 4. ed. Curitiba: Positivo Informática, 2009. Versão 6.0.

FULGÊNCIO, L. Expressões fixas e idiomatismos do português brasileiro. 2008. 489 f. Tese (Doutorado em Lingüística e Língua Portuguesa) - Pontifícia Universidade Católica de Minas Gerais, Belo Horizonte, 2008. Disponível em: <http://www.biblioteca.pucminas.br/ teses/Letras_FulgencioLM_1.pdf $>$. Acesso em: 20 set. 2014.

FULGÊNCIO, L. Dicionário de expressões fixas do português brasileiro contemporâneo. (inédito)

GROSS, G. Les expressions figées en français. Paris: Ophrys, 1996.

HENRIQUES, E. R; GRANNIER, D. M. Interagindo em português. Brasília: Thesaurus, 2001. V. 1.

MEL'ČUK, I. Phrasemes in language and phraseology in linguistics. In: EVERAERT, M.; LINDEN, E.; SCHENK, A.; SCHREUDER, R. (ed.) Idioms: structural and psychological perspectives. Hillsdale (NJ): Lawrence Erlbaum Associates, 1995. p. 167-132.

PERINI, M. A. et al. O sintagma nominal em português: estrutura, significado e função. Revista de Estudos da Linguagem, Belo Horizonte, v. 5, n. esp., p. 1-180, 1996. Disponível em: <http://www.periodicos. letras.ufmg.br/index.php/relin/issue/view/409>. Acesso em: 20 set. 2014. RIVA, H. C. Dicionários das expressões idiomáticas mais usadas no Brasil. Curitiba: Appris, 2013.

ROCHA, C. M. C.; SILVA, M. C. P. Protótipo de um dicionário semibilíngue de somatismos do português do Brasil para aprendizes argentinos. In: CONGRESSO INTERNACIONAL DE ESTUDOS DO LEXICO E SUAS INTERFACES, I, 2014, Araraquara. Caderno de resumos. Araraquara: FCL-UNESP, 2014, p. 137.

TAGNIN, S. E. O. Expressões idiomáticas e convencionais. São Paulo: Ática, 1989.

TAGNIN, S. E. O. O jeito que a gente diz. Barueri: Disal, 2013. 